\title{
Patterns of wind-drifted snow on the Alaskan arctic slope, detected with ERS-1 interferometric SAR
}

\author{
Shusun LI, ${ }^{1}$ Matthew STURM ${ }^{2}$ \\ ${ }^{1}$ Geophysical Institute, University of Alaska Fairbanks, Fairbanks, Alaska 99775-7320, U.S.A. \\ E-mail:sli@asf.alaska.edu \\ ${ }^{2}$ U.S. Army Cold Regions Research and Engineering Laboratory, P.O. Box 35170, Fort Wainwright, Alaska 99703-0170, U.S.A.
}

\begin{abstract}
We tested whether spaceborne interferometric synthetic aperture radar (InSAR) could be used to reveal patterns of redistribution of wind-drifted snow in arctic Alaska. Based on a simple geometric model, we found that lateral variations in new-snow (assuming a density of $0.3 \mathrm{~g} \mathrm{~cm}^{-3}$ ) accumulation of $>11 \mathrm{~cm}$, or redistribution of the existing snow into dunes of half this height, could produce decorrelation of C-band interferograms. Comparison of interferograms with field observations for two periods from winter 1993/94, one with wind but little new snow, and the second with wind and new snow, indicates the interferograms delineated areas where the snow depth had changed due to drifting. Striking patterns of windward scouring and leeward deposition were revealed. The interferograms also showed that during one high-wind event, conspicuous interferometric bands a few kilometers wide and $30 \mathrm{~km}$ long were formed downwind of a mountain ridge. We speculate that these bands were caused by large-scale alterations in the concentrations of moving snow particles, a finding consistent with ground observations of alternating bands of clear air and blizzard for the same area and similar to phenomena observed with the Advanced Very High Resolution Radiometer and the Geodetic Earth Observing Satellite during blizzards in North Dakota and Iowa, U.S.A.
\end{abstract}

\section{INTRODUGTION}

Winter on the arctic slope of Alaska, U.S.A., lasts for 9 months each year. There, new and recent snow, which is cold, dry and possesses minimal resistance to erosion by the wind, is frequently drifted and blown about (Benson and Sturm, 1993). These arctic snow-wind interactions are of interest because the strong winter winds cause significant sublimation losses (Liston and Sturm, 1998) and produce critical changes in the snow depth distribution (Benson and Sturm, 1993; Sturm and others, 2001). The redistribution into drifts and scoured areas impacts the winter energy balance (Taras and others, 2002) and the energy and moisture balance during the snowmelt. For example, deep drifts take longer to melt, and prolong the spring run-off, while plants in wind-scoured areas can be killed by desiccation and wind abrasion. The uneven depth distribution resulting from drifting affects the timing of the exposure of soil and plants, and plays a key role in the complex of processes that control the depth of the active layer, plant growth, and decomposition and nutrient mineralization in the soil.

Previous field investigations have shown that terrain relief of $1 \mathrm{~m}$ or more is sufficient to create drifts (Benson and Sturm, 1993; Sturm and others, 2001), but even in the absence of such topographic relief, the formation of snow dunes, barchans and sastrugi at the snow surface (Doumani, 1967) still produces a snow cover that varies in depth by a factor of two or more over distances as short as a few meters. While the physical controls that create local variations in snow depth due to drifting are reasonably well understood (Kuz'min, 1963; Tabler, 1975; Liston, 1986; Pomeroy and Gray, 1995), larger- scale patterns of redistribution are still poorly known. This ignorance arises primarily from the absence of any easy method of "visualizing" the patterns. Here, we describe a remote-sensing method based on interferometry that allows us to "visualize" changes in depth resulting from wind and snow storms over large areas.

In general, determining remotely the overall depth or water equivalent of a snow cover has proven to be problematic (Foster and others, 1996; de Sève and others, 1997; Goita and others, 1997), but the development of satellite interferometric methods has suggested the possibility of detecting subtle changes in depth associated with wind redistribution. Interferometric synthetic aperture radar (InSAR), available via the European Space Agency's (ESA) first and second European Remote-sensing Satellites (ERS-1 and -2), has provided all-weather and day-night capabilities for detecting subtle Earth surface changes (Carsey and others, 1989; Goldstein and others, 1993; Massonnet and others, 1993). In essence, ERS-1 InSAR is a technique suitable for measuring pixel-bypixel radar path-length differences between acquisitions if the satellite repeats its orbital position to within a few hundred meters (Massonnet and others, 1993; Massonnet and Feigl, 1998). The radar path-length differences, presented in terms of interferometric phases that can be measured with accuracy on the order of a fraction of the incident radar wavelength, indicate where subtle changes have occurred. Because ERS SAR operates at a wavelength of $5.65 \mathrm{~cm}$, ERS InSAR is sensitive to small changes in snow water equivalent (SWE) on the order of a few centimeters (Guneriussen and others, 2000, 2001), which makes it suitable for studying patterns of snow redistribution due to drifting. The method, however, requires 

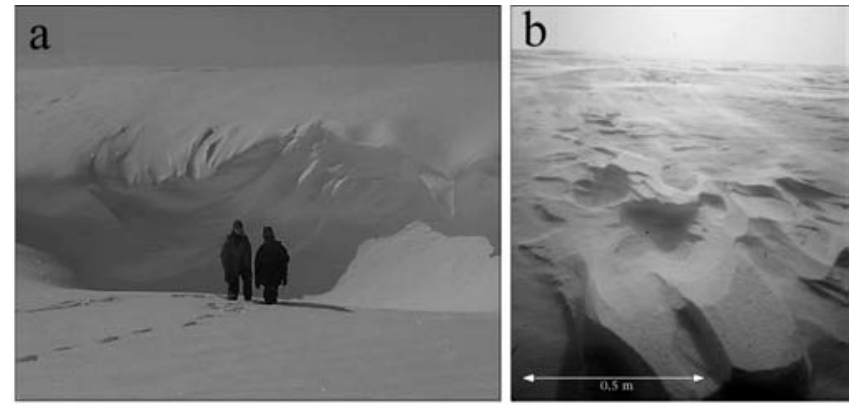

Fig. 1. (a) A large drift in the lee of a stream cutbank (drift facies). (b) Eroded snow dunes (sastrugi) on level tundra (veneer facies).

that a snowdrifting event be bracketed by two repeat orbit overpasses of the ERS SAR.

\section{TWO TYPES OF DRIFT SNOW}

The ease with which a change in snow cover due to drifting can be detected depends on the type of drifted snow. There are basically two main types, though a wide range of intermediate forms also exist. In the first type (Fig. la), the snow is transported horizontally until it comes to rest in the lee of a deep cutbank, bluff or other sharp break. Over the winter, a large drift grows. As it does, the location of maximum snow depth moves outward and downwind (Sturm and others, 2001). Width changes of $10 \mathrm{~m}$ or more, and depth changes on the order of $5 \mathrm{~m}$, are possible, so this type of drift is potentially easy to detect. The change in depth with time is unidirectional and predictable because erosion rarely removes the drift after it is deposited. In the second type (Fig. 1b), undulating horizontal layers of wind slab and small dunes form on level terrain. These layers build up, erode, and change throughout the winter. Undulations in the snow surface are linked from one layer to the next in a complex fashion; dunes and sastrugi built during one wind event may trap snow in the next event so that the local maxima migrate downwind, or the dunes may be eroded and scoured away during the next wind event, leading to topographic inversion.

Benson and Sturm (1993) have called these two types of wind deposits the drift and veneer facies, respectively, of tundra snow (Sturm and others, 1995). The veneer facies, usually $<1 \mathrm{~m}$ deep, is characterized by a few hard, high-density, wind-packed snow slabs interlayered with coarse, lowerdensity depth-hoar layers at the base of the snow and between the slabs. The drift facies, consisting of wedgeshaped layers of snow, is entirely composed of dense slabs without intervening layers of depth hoar. In the veneer facies, dunes and sastrugi create surface roughness and relief 0.1-0.7 $\mathrm{m}$ in height and up to $10 \mathrm{~m}$ in length. Sastrugi, the result of wind erosion of older dunes and barchans, has similar dimensions. "Whalebacks", streamlined dunes elongated parallel to the wind and often polished on top, are similar in height to other dunes, but can reach lengths of $20 \mathrm{~m}$ or more.

\section{DETEGTION OF SNOW AND DRIFTING USING ERS-1 InSAR}

\section{Radar interaction with cold dry snow}

In a cold dry snow cover, the main impact of the wind is on the top layer of snow. The lower layers experience little or no change due to the wind because they are protected. These layers therefore have little impact on the pattern of interferograms, and we need to concern ourselves only with radar propagation within the top snow layer. On Alaska's arctic slope, the top snow layer is mainly composed of wind slabs consisting of fine-grained $(\sim 0.1 \mathrm{~mm})$ snow particles.

When a radar beam passes through snow, it experiences scattering, absorption and refraction. Since the ERS-1 SAR operates at C-band, its wavelength of $5.65 \mathrm{~cm}$ is much larger than the size of snow grains. Volume-scattering effects caused by snow particles, whose physical size typically ranges from 0.1 to $1 \mathrm{~mm}$ in arctic snow, are small. Also, the dry arctic snow is only slightly absorptive to C-band microwave (Ulaby and others, 1986), so it is basically transparent to radar penetration given the relatively thin snow thickness on the Alaskan arctic slope. Only large melt clusters (rarely found in arctic snow), extremely large depth-hoar crystals (sometimes present), ice lenses (rare), vegetation, rough ground surface beneath the snow, and scatterers in the soil contribute in any substantial way to the signature intensity received by the SAR. The main effect of the snow on the SAR, therefore, is refraction, which causes bending of the propagation direction towards the snow surface normal, a reduction of wavelength within the snow layer, and a resulting excess phase delay in propagation through the snow.

Based on snow-microwave interaction theory (Ulaby and others, 1986), the refractive index of a material, $n$, is the real part of the square root of the complex dielectric constant $\varepsilon$ :

$$
n=\operatorname{Re}\{\sqrt{\varepsilon}\},
$$

where $\varepsilon=\varepsilon^{\prime}+\varepsilon^{\prime \prime}, \varepsilon^{\prime}$ is permittivity, and $\varepsilon^{\prime \prime}$ is the dielectric loss factor.

The dielectric constant of dry snow is independent of frequency in the $10 \mathrm{MHz}-10 \mathrm{GHz}$ range, and the real part depends on snow density only (Mätzler, 1996):

$$
\varepsilon_{\mathrm{ds}}^{\prime}=1+1.6 \rho_{\mathrm{s}}+1.8 \rho_{\mathrm{s}}^{3},
$$

where $\varepsilon_{\mathrm{ds}}^{\prime}$ is the real part of the complex dielectric constant, or permittivity, of dry snow, and $\rho_{\mathrm{s}}$ is the density of snow relative to water, a dimensionless quantity.

Because the imaginary part (or dielectric loss factor) of dry snow is very small, the refractive index of dry snow is given by $n_{\mathrm{ds}} \cong \sqrt{\varepsilon_{\mathrm{ds}}^{\prime}}$. Based on this relation, a snow layer with a density of $0.3 \mathrm{~g} \mathrm{~cm}^{-3}$ would have a refractive index of 1.24. For a radar beam with an incidence angle of $0^{\circ}$, a $100 \mathrm{~cm}$ thick snow layer with such a density would produce a path length equivalent to $124 \mathrm{~cm}$ in a vacuum, which is an increase in radar path length by $24 \%$.

\section{Model for interferometric phase and coherence analysis}

The addition of a uniform layer of snow between repeat acquisitions of SAR imagery will change the radar propagation direction, wavelength and speed. This will cause an extra phase term when the radar phase delay is compared pixel by pixel between the two co-registered complex SAR images. The phase difference between these two co-registered pixels is called the interferometric phase, and the resulting pixelby-pixel image is an interferogram. On an interferogram, the interferometric phase value at each pixel can be decomposed into three basic terms: the topographic term, the surface change term and the noise term (Massonnet and Feigl, 1998). The topographic term is proportional to surface elevation and 


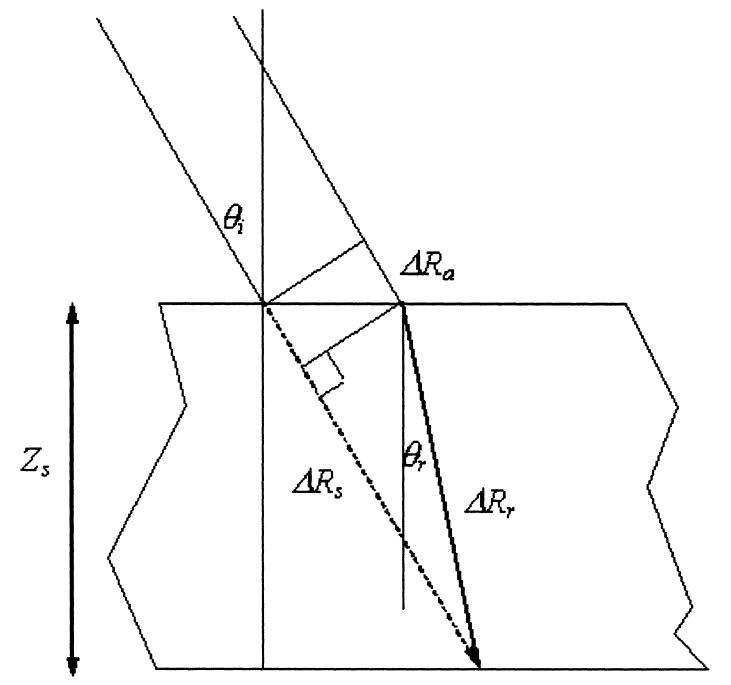

Fig. 2. Geometry of refraction in dry snow (after Guneriussen and others, 2001, fig.1).

satellite baseline. The noise includes SAR system and processing noise, which appears as random noise, plus atmospheric and ionospheric effects, which usually exhibit variations at scales larger than a few kilometers. The surface change term in our particular investigation is related to changes in the snow cover.

Guneriussen and others $(2000,2001)$ provide the theoretical relation between interferometric phase and changes in SWE of dry snow. The snow phase term, which represents the radar phase difference in the two-way propagation with and without snow, can be evaluated using Figure 2:

$$
\Phi_{\mathrm{s}}=-\frac{4 \pi}{\lambda_{\mathrm{i}}} Z_{\mathrm{s}}\left(\cos \theta_{\mathrm{i}}-\sqrt{\varepsilon_{\mathrm{ds}}^{\prime}-\sin ^{2} \theta_{\mathrm{i}}}\right),
$$

where $\lambda_{\mathrm{i}}$ is radar wavelength in vacuum, $\theta_{\mathrm{i}}$ is incidence angle and $Z_{\mathrm{s}}$ is depth of snow cover.

According to Equation (3), variation in the thickness of the new snow accumulation $\left(Z_{\mathrm{s}}\right)$ will cause a change in the interferometric snow phase term. Based on Equations (2) and (3), variation in the snow density will cause a similar change. The two effects combined lead to a relatively simple relation between the interferometric snow phase term and the SWE (Guneriussen and others, 2001). For ERS repeatpass interferometric SAR with a nominal radar incidence angle of $23^{\circ}$, this relation is:

$$
\Delta \Phi_{\mathrm{s}}=\frac{4 \pi}{\lambda_{\mathrm{i}}} \times 0.87 \Delta \mathrm{SWE} .
$$

Because Equation (4) indicates that the variation in interferometric snow phase term is proportional only to a change in SWE for a given radar wavelength, the equation can be extended to other events in addition to the deposition of new snow, including snowdrifting between repeat acquisitions of SAR images. The simple relation in Equation (4) forms the basis of our detection of snowdrifts using interferograms derived from ERS SAR images.

We want to examine what happens to an interferogram when substantial lateral variations in snow layer thickness are introduced between SAR acquisitions, such as might occur when there is wind drifting. Assuming a constant snow density (and therefore a constant dielectric constant), the sensitivity of interferometric phase to a variation of snow thickness can be evaluated by a parameter, $d$, defined as the variation in snow thickness needed to produce a $2 \pi$ interferometric phase variation:

$$
d=\frac{\lambda_{\mathrm{i}}}{2\left(\cos \theta_{\mathrm{i}}-\sqrt{\varepsilon_{\mathrm{ds}}^{\prime}-\sin ^{2} \theta_{\mathrm{i}}}\right)} .
$$

For a typical dry snow cover with a density of $0.3 \mathrm{~g} \mathrm{~cm}^{-3}, d$ equals $11 \mathrm{~cm}$ for ERS-1 InSAR, or about $3.3 \mathrm{~cm}$ SWE. Where drifting has produced adjacent areas of erosion and deposition with a relief difference of $11 \mathrm{~cm}$, a $2 \pi$ interferometric phase variation will be introduced. We want to stress that if a perfectly uniform snow slab of $11 \mathrm{~cm}$ (or any thickness) is added, the interferometric result will be indistinguishable from the case of no change in the snow cover.

Nevertheless, the effects of lateral variations in snow layer thickness on the interferometric phase can be evaluated using the estimate of coherence $(\gamma)$ (Zebker and Villasenor, 1992):

$$
\gamma=\frac{\left|\sum_{n=1}^{N} C_{1} \overline{C_{2}}\right|}{\left(\sum_{n=1}^{N} C_{1} \overline{C_{1}} \sum_{n=1}^{N} C_{2} \overline{C_{2}}\right)^{1 / 2}} \quad 0 \leq \gamma \leq 1
$$

where $\bar{C}_{n}$ is the complex conjugate of $C_{n}$, and $C_{1} \bar{C}_{2}$ is the pixel-by-pixel phase difference in the neighborhood. Coherence is a good measure of the temporal change between acquisitions at a pixel when terrain effects and SAR system and processor errors are minimal. A value 1 indicates a perfect match. Since estimation of coherence from interferograms using Equation (6) often overestimates coherence for low-coherence areas (Bürgmann and others, 2000), in our practice a coherence value around 0.25 or lower is usually taken to indicate no similarity in the returning phase patterns between SAR acquisitions. Resulting coherence maps can be used to detect changes. When the snowpack has undergone little or no change, the coherence will be high. High coherence might also be maintained for the deposition of a perfectly uniform new snow slab in ideal circumstances. Any heterogeneous irregularities in the thickness of the layer, however, will cause variations in the interferometric phase values. This explains why new snow, which is rarely of uniform thickness, tends to reduce interferometric phase coherence. The same analysis can be applied to irregular erosion and deposition. Complete decorrelation occurs when the adjacent erosion/deposition features differ in relief by $11 \mathrm{~cm}$.

Let us suppose that a set of snow dunes of peak height $H>d / 2$ are migrating downwind. When the dunes have migrated such that at some point the snow layer thickness has increased by $d / 2$, at a nearby adjacent point it will have decreased by $-d / 2$. For a pixel containing both points, the combined change in depth will be $d$, and complete decorrelation in interferometric phase will have occurred. If the original distribution of dunes within the pixel in an area was random and the migration causes reverse in surface relief, then the probability that the pixel surface height will change by an amount $\Delta h$ at a fixed point is $\Delta h / 2 H$. The average height change for the entire pixel is zero unless there has been new snow, but the distribution of deep and shallow areas is now different. At any fixed point the possible range of height changes due to downwind migration is $\pm H$, or $2 H$. 


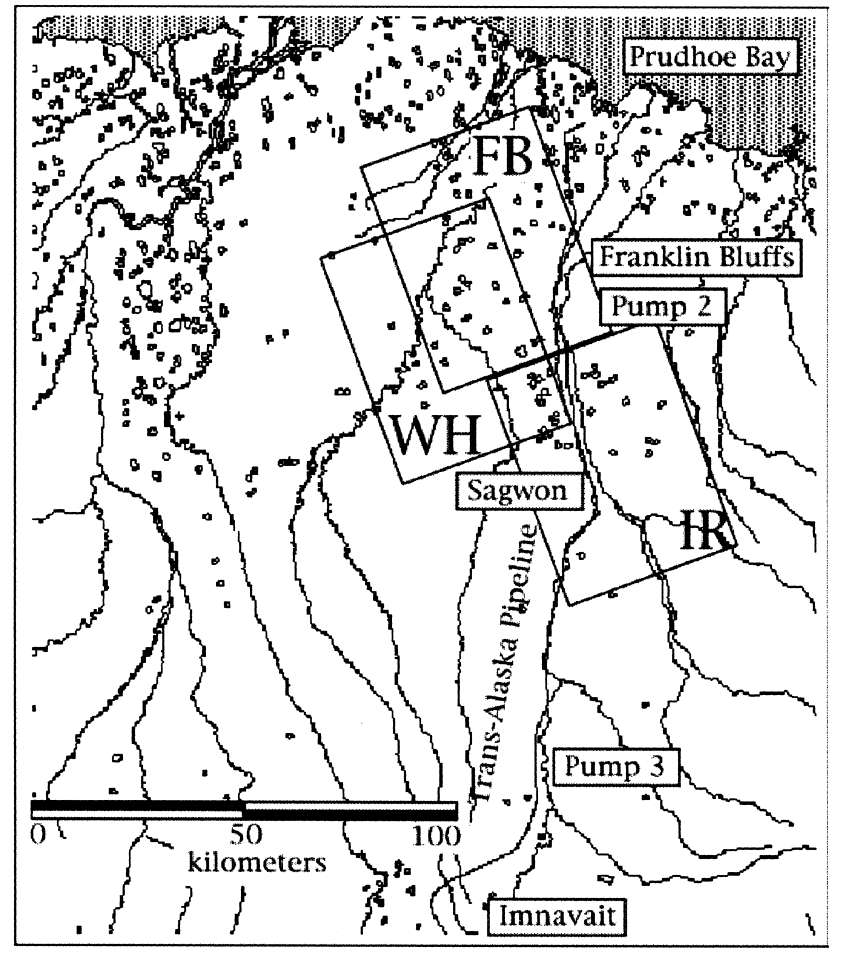

Fig. 3. The Kuparuk River basin in northern Alaska, showing the three InSAR sites (IR, WH, FB) used in the study, as well as general locations for snow pits ( Fig. 4).

In general, the rms of surface roughness is related to the height of the dunes as follows:

$$
h_{\mathrm{rms}}=\sqrt{\frac{1}{2 H} \int_{-H}^{H} h^{2} \mathrm{~d} h}=\sqrt{\frac{1}{3}} H=0.58 H .
$$

According to Bamler and Hartl (1998), a rms of $1.8 \mathrm{rad}$ or more in interferometric phase in a window around a pixel will cause a complete phase decorrelation at the pixel location. The critical rms of surface roughness of a migrating dune that causes interferometric decorrelation can be derived using either the relation between interferometric phase term and snow thickness phase or the relation between $d$ and the height of snow dunes:

$$
\begin{aligned}
h_{\mathrm{rms}}^{\mathrm{cr}} & =\frac{1.8}{2 \pi} d=0.29 d \\
h_{\mathrm{rms}}^{\mathrm{cr}} & =\sqrt{\frac{1}{d} \int_{-d / 2}^{d / 2} h^{2} \mathrm{~d} h}=\sqrt{\frac{1}{12}} d=0.29 d .
\end{aligned}
$$

Both approaches lead to the same results. If the height of the migrating dunes, $H$, reaches half of the critical snow thickness, $d$, or the rms of the surface roughness of migrating dunes, $h_{\mathrm{rms}}^{\mathrm{cr}}$, reaches $0.29 d$, then the interferogram will show complete decorrelation. In other words, moving barchans or sastrugi with a roughness rms of $3.2 \mathrm{~cm}$ or rougher, or with a height about $5.5 \mathrm{~cm}$ or higher, will produce this result.

\section{RESULTS}

\section{Study area and interferometric data processing}

Three sites (Fig. 3) were selected along the Sagavanirktok River on the arctic slope of Alaska for our study. For each site, we obtained a sequence of ERS-1 InSAR products. From south to north the sites were named Ivishak River (IR), White Hills (WH) and Franklin Bluffs (FB). They roughly define a north-south strip $100 \mathrm{~km}$ long and $70 \mathrm{~km}$ wide that stretches from the northern foothills of the Brooks Range to the coastal plain near Prudhoe Bay on the Arctic Ocean. The overlap among the sites (Fig. 3) allowed for cross-calibration of the SAR interferograms. A wide variety of terrain was encompassed, including flat and rolling tundra, river valleys, and hills with different slopes and aspects. In addition, the sites included both the thinner, more wind-drifted snow of the arctic coastal plain and the thicker, less wind-drifted snow of the foothills north of the Brooks Range (König and Sturm, 1998; Taras and others, 2002).

The SAR data were acquired between 8 January and 27 March 1994 when the ERS-1 was in its second ice phase (Carsey and others, 1989). During this period, the ERS-1 satellite repeated $82 \%$ of its orbits to within $0.6 \mathrm{~km}$ every 3 days (Solaas, 1994). According to the basic theory of InSAR (Zebker and Goldstein, 1986; Li and Goldstein, 1990; Zebker and others, 1994; Massonnet and Feigl, 1998), for ERS C-band SAR the maximum allowable baseline separation between repeat orbits, measured in a direction perpendicular to both the radar beam and satellite orbit, is about $1.1 \mathrm{~km}$. In typical InSAR processing, pairs of SAR images with their baseline separations less than half of this maximum value are likely to produce useful interferograms for change detection. For the study area during the period of our interest, all the baselines between consecutive acquisitions were within $0.5 \mathrm{~km}$, except for the pair between 16 and 25 February. This enabled us to generate a time series of 11 interferograms for each study site.

During interferometric processing, 10 by 2 pixels in the intermediate interferogram generated from a pair of single look complex (SLG) SAR images were combined to derive an average interferometric phase and associated coherence value. Because the original SLC images had a pixel spacing of 4 by $20 \mathrm{~m}$, the resulting interferograms and coherence maps had a resolution of 40 by $40 \mathrm{~m}$. The topographic phase term on the flat coastal plain was removed by a simple Earthflattening procedure (Prati and Rocca, 1990). Because the ERS SAR images used in the study have a high signal-to-noise ratio (SNR) and a stable Doppler centroid, the SAR system and processing noise was negligible. Under usual atmospheric conditions, the atmospheric effects, especially their effects on interferometric coherence, were also negligible.

Between 14 and 20 December 1993, and between 23 March and 4 April 1994, extensive measurements of snowcover characteristics were made along the north-south strip defined by the InSAR sites. In particular, at more than 20 locations along the strip including the sites labeled Pump 3 and Pump 2 in Figure 3, the snow stratigraphy was observed in pits. The stratigraphic record was compared to weather records from data loggers at Imnavait Creek, Sagwon Bluffs, Franklin Bluffs and from National Weather Service (NWS) records at Deadhorse near Prudhoe Bay (Fig. 3). The comparison allowed us to assign a deposition date to most of the snow layers. Hard slabs resulting from wind transport could be readily differentiated from the softer layers deposited during snowfall without wind.

\section{Data analysis and interpretation}

Records of snow depth, wind speed and precipitation (Fig. 4) indicate that eight key events modified or added to the snow 


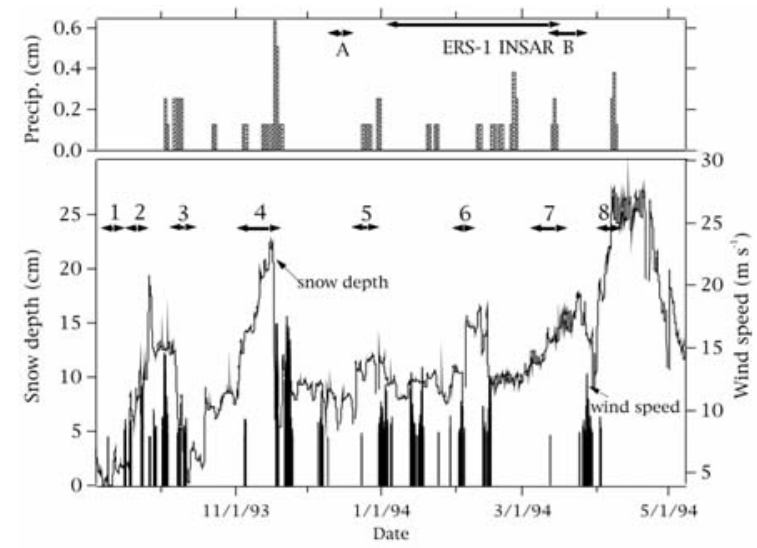

Fig. 4. Wind speed, snow depth and precipitation during winter 1993/94 for Imnavait Creek. Snow depth was recorded by an acoustical sounder; precipitation was recorded at a NRCS Wyoming sheltered gauge nearby.

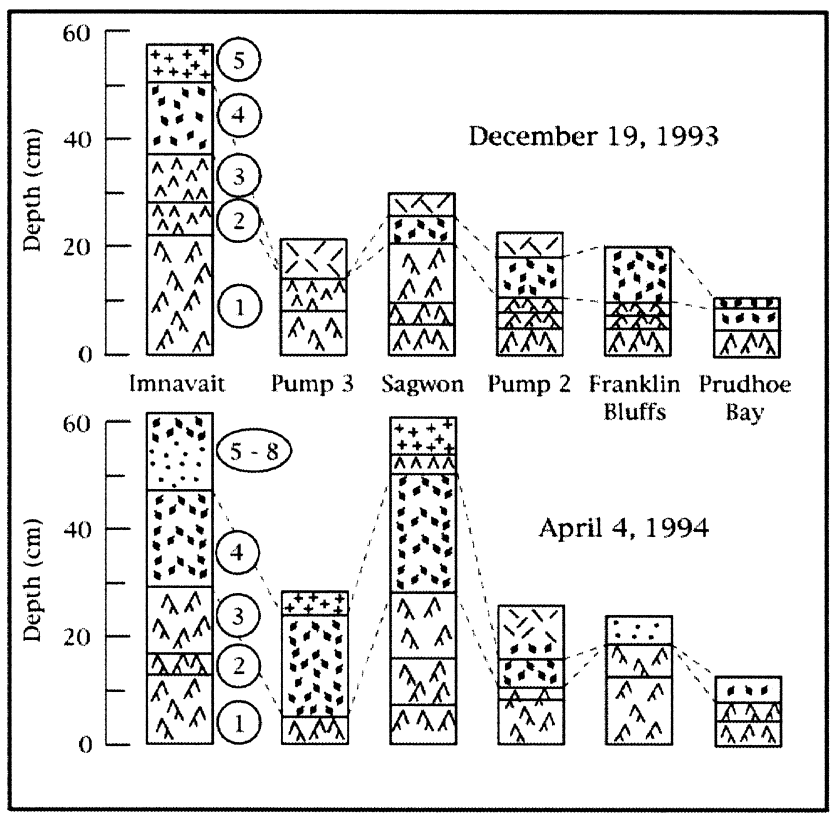

Fig. 5. Snow stratigraphy in the study area, December 1993 and April 1994. See Figure 3 for locations. Symbols are from the International Classification of Snow on the Ground (Colbeck and others, 1990).

cover during winter 1993/94. During these events, distinct changes in the snow depth were recorded at the acoustical snow-depth sensors operated at Imnavait Creek (Sturm and others, 2001). When it was snowing, the depth increased, but during high-wind events (both with and without snowfall) the snow depth increased, decreased or alternated between the two as dunes migrated under the sensor. The precipitation record (Fig. 4), recorded at a Natural Resources Conservation Service (NRCS) Wyoming gauge nearby, was subject to substantial errors in both amount and timing of precipitation (cf. Black, 1954; Goodison and others, 1981; Benson, 1982), but the record serves as a good guide for when large precipitation events occurred.

Stratigraphically, the combined wind and snow event of 1-10 November produced the most important and recognizable snow layer of the winter (Figs 4 and 5, layer No. 4), a hard, dense wind slab whose surface was sculpted into dunes and sastrugi (Fig. 1b). This slab was continuous throughout the study area, and its surface was polished and offered little lodgment for subsequent snow deposition. It was underlain

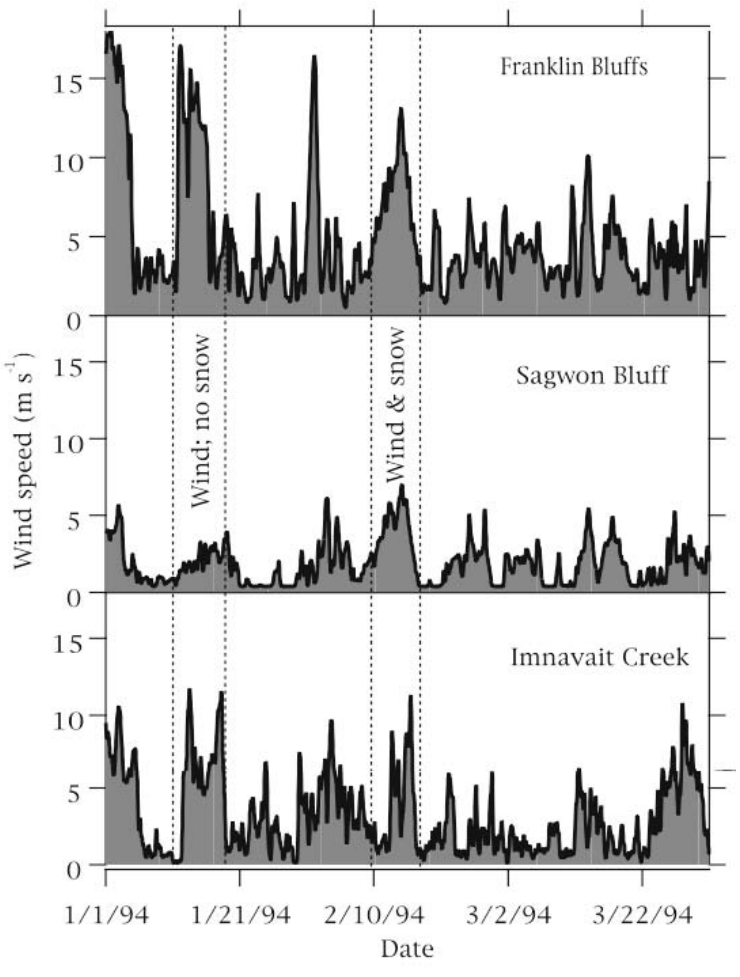

Fig. 6. The wind speed at Imanvait Creek, Sagwon Bluff and Franklin Bluffs, 1994, showing the two periods discussed in the text (dashed lines).

by three softer layers, all deposited with relatively little wind. Light snow fell on several occasions during December-February, but produced only two identifiable changes in the snow cover (Nos. 5 and 6) and surprisingly little change in the overall stratigraphy (Fig. 5). The next two events (Nos. 7 and 8) added some soft discontinuous slabs (Fig. 5), absent in several sampling locations.

We focus on two contrasting wind events, one a strong east-to-southeast wind that blew over wind-packed snow layer No. 4 without much snow available for transport (Figs 4 and 5), and the other a strong west wind that blew after a more substantial snowfall. These two events produced different patterns of wind-snow interaction in the ERS-1 InSAR sequences, consistent with our theoretical understanding.

\section{Wind with minimal snow available for transport}

On 11 January, the wind speed rose rapidly, reaching peak speeds in excess of $15 \mathrm{~m} \mathrm{~s}^{-1}$ at Franklin Bluffs and Imnavait Creek (Fig. 6). At Sagwon Bluffs, lower speeds were recorded (Fig. 6) but these were probably the result of a rimed-up anemometer. There had been no new snow since 1 January, at which time only a small amount was deposited, and this had already been worked by the high winds of 1-3 January (Fig. 6). We infer from our sonic sounders that at most a residual irregular thin snow layer of $4 \mathrm{~cm}$ covered hard wind slab No. 4 when the wind came up. The storm lasted more than 5 days (Fig. 6) and finished scouring off the little snow that covered the hard slab, depositing most of it in drifts. ERS-1 SAR acquisitions began on 8 January before the storm and continued through 14 January.

The InSAR maps (Fig. 7) for the period including the 11 January wind storm maintain high phase coherence between acquisitions for all of the flat and rolling parts of the study area. This indicates that over most of the landscape, scouring of radar sensitive scatterers was negligible. 


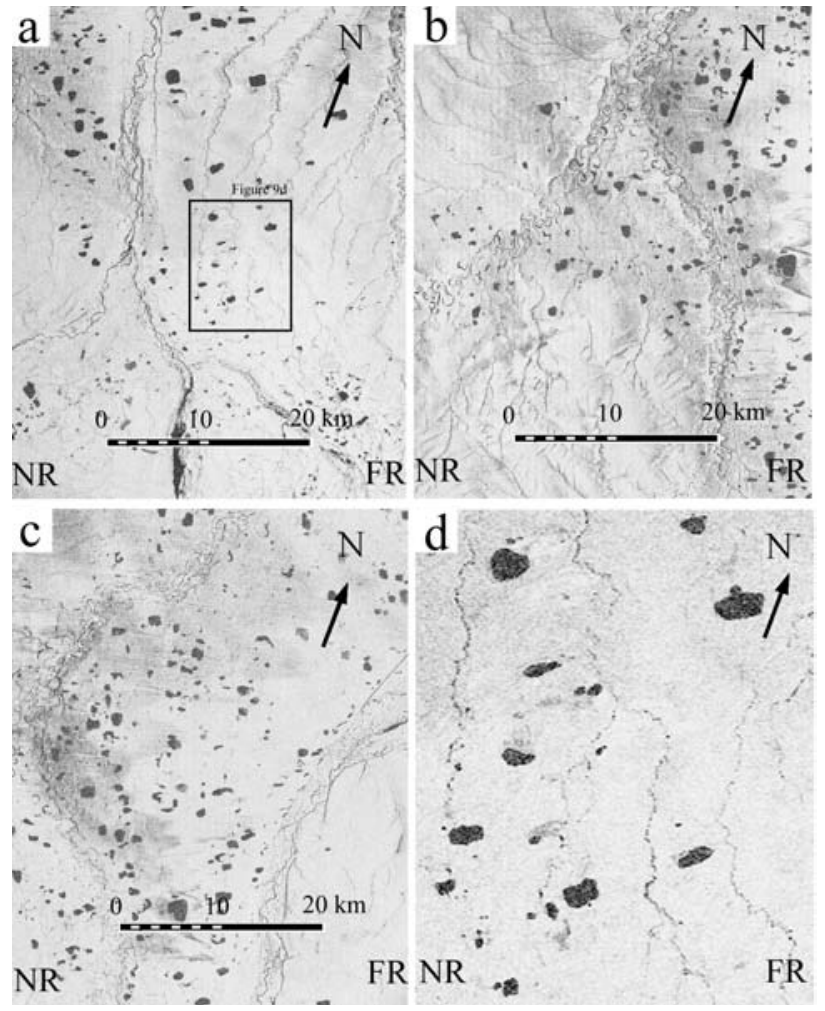

Fig. 7. Coherence images for the time period 8-14 January at (a) the Ivishak site, (b) theWhite Hills site, (c) the Franklin Bluffs site, and (d) the central part of Ivishak site. Dark tones denote low coherence; bright tones denote high coherence. Low coherence is found only in the stream courses and where there are lakes. $\mathcal{N R}$, near range; FR, far range.

The main effect of the wind storm in these areas was the removal of the thin, soft snow at the top of the pack. Its thickness, and thickness variations, were only a fraction of the critical value of $11 \mathrm{~cm}$, and, as a consequence, its removal had little impact on the radar signal. Layer No. 4 was too hard to be eroded by the wind, and it protected the three softer underlying layers. As a result, the area-wide snow stratigraphy changed little and the coherence stayed high.

In contrast, areas where there was active growth of river and lake ice changed. These areas appear dark in Figure 7. Along main river channels, such as the Ivishak River seen in the lower central part of Figure 7a, active growth of river and stream ice occurred as water pressure beneath the deepening ice cover became great enough to force water through cracks in the ice cover and the overflowing water refroze. On most lakes, the ice thickened during this period due to basal ice accretion (Jeffries and others, 1994); they also appear dark in Figure 7. A detailed discussion of why areas of active ice growth produce low phase coherence (dark areas) can be found in Li and others (1997).

More interestingly, the phase coherence for areas where the drift facies might be expected to form also dropped to low levels during the mid-January wind storm. During the period, most of the snow scoured and eroded from the veneer snow was likely deposited in the lee of ridges and bluffs or small depressions such as river channels and creeks. This would account for the low phase coherence values observed in these areas. When the January low-coherence areas are superimposed on a topographic map, they lie directly over riparian zones and small creeks, a finding that is consistent with progressive in-filling of drifts by snow blowing off the tundra. Figure $7 d$ is an enlargement of the central part of
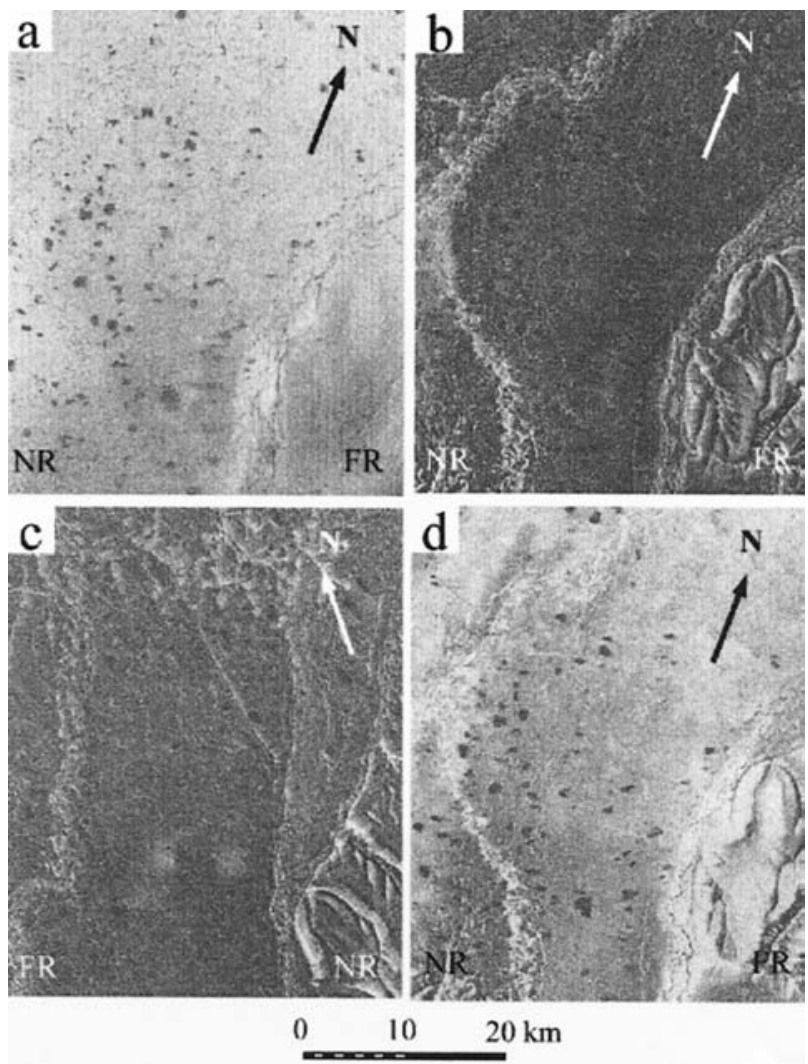

Fig. 8. Examples of coherence images in time series for the Franklin Bluffs site. The Bluff is the rougher topography in the southeast (lower right) part of the images. The time intervals involved in the interferogram generations are (a) 4-7 February; (b) 13-16 February from east-looking orbits; (c) 12-15 February from west-looking orbits; (d) 25-28 February 1994.

Figure 7a. It shows that for most small creeks the coherence is low (dark). Because in January most of these small creeks were already completely frozen, the low coherence is unlikely to be the result of active ice growth ( $\mathrm{Li}$ and others, 1997). The main cause for the low coherence in those areas was the deposition of drift snow. There are two mechanisms of snow deposition in those areas. One is cutbank drift deposition like that shown by the cornice in the background of Figure la. The other is deposition of the suspended snow load amongst the willows found in the bottom of creeks, as evidenced by the deep footprints in the soft snow in the foreground of Figure la. Because the spatial resolution of our coherence map is $40 \mathrm{~m}$ due to averaging during interferometric processing (Equation (6)), we cannot tell specifically which deposition mechanism was dominant for a particular creek. Most likely both mechanisms operated together. For the large rivers, snow deposition along cutbanks and amongst willows was probably only a second-order process in producing low coherence, masked by the active growth of river ice.

\section{Wind with snow available for transport}

We now look at a period when there were strong winds but also more snow for transport. During this period, the snow surface changed by an amount greater than the critical thickness, revealing large-scale spatial variations in the redistribution of the snow (Fig. 8). According to the weather and snow records, little or no new snow fell in the month prior to February 1994. On 5 February, based on the sonic sounders, about $7 \mathrm{~cm}$ of snow fell on the region (event No. 6 in Fig. 4). Immediately following this snowfall, there was a 


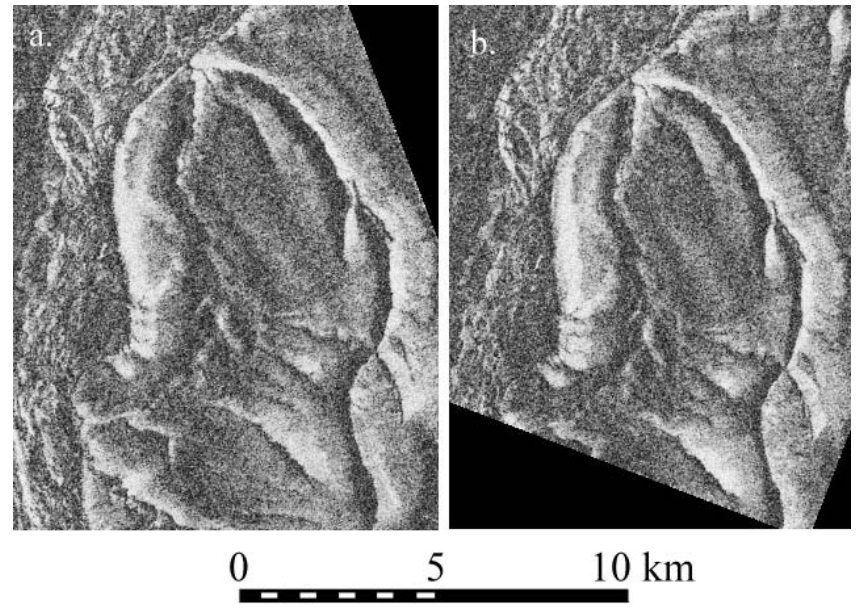

Fig. 9. Enlargements of the lower right parts of Figure $8 b$ and $c$ with their orientation aligned.

brief period of calm during which the coherence maps (Fig. 8a) showed little change in either the veneer snow on the tundra or drift snow in the creeks and rivers. Only the lakes, where the ice thickness continued to increase, showed low coherence values (dark). This widespread absence of change during a relatively uniform accumulation of new snow is consistent with our previous discussion.

Between 10 and 15 February, however, persistent strong westerly winds with speeds reaching $12 \mathrm{~m} \mathrm{~s}^{-1}$ swept the area (Fig. 6). By 14 February, all $7 \mathrm{~cm}$ of the new snow under the sonic sounders had been removed at the Imnavait site (Fig. 4). For this period, the coherence maps show a distribution pattern of alternating light and dark strips that are strongly correlated with topography and aspect with respect to the wind. The patterns cannot be explained by artifacts caused by radar and terrain interactions; identical patterns are seen on all east-looking interferograms derived from ascending satellite passes (e.g. Figs $8 \mathrm{~b}$ and $9 \mathrm{a}$ ) and also on the one available west-looking interferogram derived from descending passes (Figs 8c and 9b). As an example, around Franklin Bluffs, high coherence was observed on west-facing slopes while low coherence was observed on east-facing slopes, though the subtle details of the snow distribution are more complicated. We interpret these patterns to be widespread areas of windward scour and leeward deposition. To our knowledge, the coherence maps are the first time that such patterns have been "visualized" in this detail over such a large scale.

We can explain a number of the more subtle observed coherence features (Fig. 9) in a manner that is consistent with our understanding of snowdrifting. On the flat tundra to the west of Franklin Bluff, the coherence was low, most likely caused by the migration of snow dunes, barchans and sastrugi over the veneer snow. A narrow north-south strip of even lower coherence (dark) immediately at the base of the west-facing bluff suggests to us an area of considerable snow deposition. The west wind must have carried a large amount of snow in transport after traveling across the vast tundra plain to the west of the bluff. It may have dumped this load at the base of the bluff due to an upwind snow-fence effect (Tabler, 1980). In a narrow strip near and at the top of the bluff and surrounding hills, a zone of wind-scoured terrain remained basically unchanged throughout the period. In these wind-exposed locations, new snow is scoured away almost immediately after it is deposited, an effect which produced the north-south band with high phase coherence

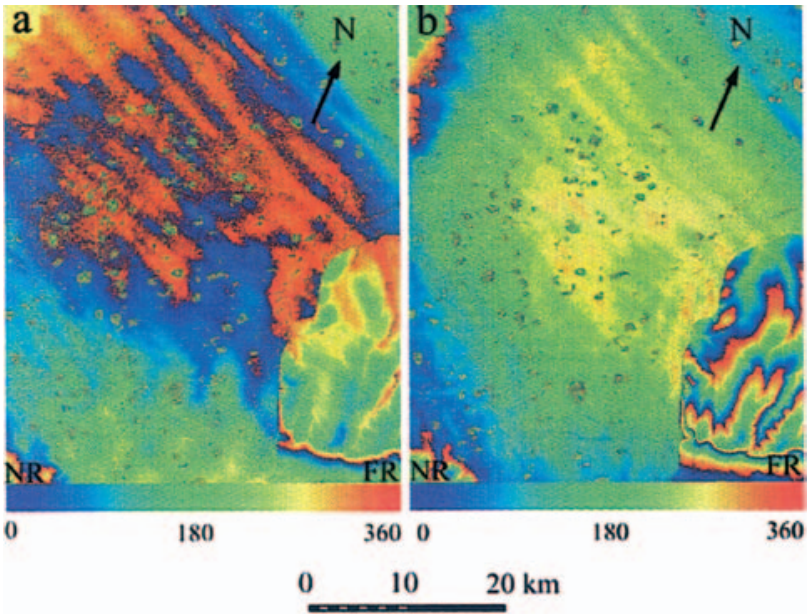

Fig. 10. Interferometric phase images of the Franklin Bluffs site generated from image pairs of (a) 8-14 January 1994 and (b) 14-20 Fanuary 1994.

at the top of the bluff. Further east, the wind deposited snow on east-facing slopes. Snow deposition, and perhaps development of dunes, created a narrow band of low phase coherence there. On the second row of west-facing slopes, we speculate that the wind had lost some of its scouring power due to the relatively short fetch between the ridge crests. The weaker wind left substantial amounts of snow over the relatively wide and flat area, producing a second zone of relatively low coherence. The subsequent weak winds that followed the wind storm of 10-15 February did not change the large-scale pattern of snow deposition and erosion shown in Figure 8b and c, but did produce some short-distance transportation of snow and the migration of snow dunes and sastrugi. These local changes in snow distribution produced the pattern of phase coherence for the time period 16-28 February shown in Figure 8d. Enlargements (Fig. 9a and b) of the lower right parts of Figure $8 b$ and c highlight the similarity between the two dates and show details of the snow redistribution.

The most important implication of Figures 8 and 9 is that InSAR provides a method of visualizing the interaction of wind, terrain and snow transport at a variety of spatial scales. Our results show that the details of those interactions are temporally and spatially complicated, depending on terrain steepness, wind speed, direction, as well as the previous history of snow transport. The interaction between wind and snow seems to show a downwind attenuation that is due in part to changes in snow supply, in part due to increased snowpacking, and in part due to diminishing wind speeds (Fig. $8 \mathrm{~b}$ and d). Combined, a complicated picture of transport emerges.

\section{Wind bands}

Distinctive bands or streaks parallel to the wind appear downwind of Franklin Bluffs on interferograms, but only on those that include the acquisition of 14 January 1994 (Fig. 10) as one of the SAR pair. Some sort of atmospheric effect on 14 January is suggested (cf. Massonnet and Feigl, 1998). Possible explanations are either airborne snow or ionospheric effects.

Favoring the airborne-snow hypothesis is that on 14 January, blowing snow and limited visibility was reported at the Prudhoe Bay airport (Fig. 3), while the wind at a meteorological site on the lower Kuparuk (data not shown) was 
$>15 \mathrm{~m} \mathrm{~s}^{-1}$ from the east-southeast, well in excess of what is needed to transport snow. At the Imnavait and Franklin Bluffs sites, the winds were high: 9 and $15 \mathrm{~m} \mathrm{~s}^{-1}$, respectively (Fig. 6). The interferometric bands were oriented $110^{\circ}$, basically parallel to the wind direction $\left(100^{\circ}\right)$ at Franklin Bluffs and on the lower Kuparuk. A total of 10 streaks, each about $3 \mathrm{~km}$ wide, were seen in a 30 by $30 \mathrm{~km}$ area.

SAR banding of ionospheric origin has been observed by Joughin and others (1996) and explained by Gray and others (2000). These bands, which are observed close to the radar range direction, are the result of additional phase variation that occurs when the radar wave propagates through vertical sheets of fluctuating ionospheric electron density within the auroral zone. Two facts suggest that the banding observed near Franklin Bluffs (Fig. 10) was not of this origin. First, the ionospheric activity during the SAR acquisition (GMT 07:22:11-07:22:23 on 14 January 1994) was low. The auroral electrojet index (AE: Davis and Sugiura, 1966) was 455 (http://swdcdb.kugi.kyoto-u.ac.jp/aedir/download.html), nearly background level. Second, the streaks or bands that were observed were about $45^{\circ}$ to the SAR range direction.

If we discard an auroral origin for the bands, and accept that the coincidence of the banding with the blowing-snow direction suggests a wind/snow origin, then by what mechanism are the bands formed? We suggest that the bands were the result of "bands" of different concentrations of saltating and suspended snow particles in the air. The $3 \mathrm{~km}$ width and long downwind extension of the streaks favor this hypothesis, which is also consistent with field observations. On several occasions, we have been caught driving near Franklin Bluff during blizzards. At these times we have driven through alternating zones where one moment the visibility on the road was frighteningly reduced due to blowing snow, and in the next moment it was clear with no blowing snow at all. In both zones the wind speed was high. The zones were 0.5 to $>2 \mathrm{~km}$ wide. On the ground there was no way to have known that these zones had such a long downwind extension, but the interferogram (Fig. 10) suggests that they may have been $>30 \mathrm{~km}$ long.

We can investigate how much snow would have had to be in transport, using the interferometric phase difference from Figure 10. The phase difference between the streaks and inter-streaks is about $30^{\circ}$, or one-twelfth of a wavelength for a round-trip radar path. Such a phase delay can be quantified using basic radar-snow interaction theory (Ulaby and others, 1986; Mätzler, 1996). Because the mass concentration of airborne snow is very small in any case, the refractive index of the lower atmospheric layer of interest can be evaluated using the first derivative of refractive index as a function of mass concentration (or density relative to water, $\rho_{\mathrm{as}}$ ) of airborne snow based on Equations (1) and (2):

$$
n_{\mathrm{as}}(z)=1.0+0.8 \rho_{\mathrm{as}}(z) .
$$

This leads to an expression for calculation of the total extra round-trip radar path length caused by airborne and saltating snow, $\Delta R$ :

$$
\begin{aligned}
\Delta R & =2 \frac{\int_{0}^{\infty}\left(n_{\text {as }}(z)-1\right) \mathrm{d} z}{\cos \theta}=2 \frac{\int_{0}^{\infty} 0.8 \rho_{\text {as }}(z) \mathrm{d} z}{\cos \theta} \\
& =1.6 \frac{\int_{0}^{\infty} \rho_{\text {as }}(z) \mathrm{d} z}{\cos \theta}
\end{aligned}
$$

where the term $\cos \theta$ is included to account for the effect of slant incidence of radar beams. The SWE of the suspended snow particles in the atmospheric column is

$$
\mathrm{SWE}=\int_{0}^{\infty} \rho_{\mathrm{as}}(z) \mathrm{d} z=\frac{\cos \theta}{1.6} \mathrm{~d} R=0.58 \Delta R .
$$

For a $30^{\circ}$ phase difference between bands and inter-bands seen on the ERS-1 SAR interferograms, the total round-trip radar path-length difference $(\Delta R)$ equals $0.47 \mathrm{~cm}$. This leads to a SWE difference of $0.27 \mathrm{~cm}$ for atmospheric columns in bands and inter-bands. Assuming the atmosphere in the interstreaks is free of saltating and suspended snow particles, then the streaks themselves must contain $0.27 \mathrm{~cm}$ of SWE in the atmosphere. This is a concentration about five times higher than would be predicted from standard equations for snow transport by saltation and suspension in the boundary layer (Pomeroy and Gray, 1995; Liston and Sturm, 1998).

We are unsure why such a large discrepancy exists, but still believe that differences in the atmospheric concentration of moving snow particles are the most likely source of the interferometric streaks. We note that snow-transport theories do not account for "rivers of drift", and that if half of the air is clear of drifting snow the other half might have twice the predicted concentration, reducing the discrepancy by $50 \%$. It is also possible that the full atmospheric column seen by the ERS-1 SAR contains a greater amount of snow than the theories predict. Similar streaks resulting from blowing snow have been observed using other satellite sensors, so we think it unlikely that our observations are an artifact of InSAR processing. On 15 January 1997, "banding” on streaks of blowing snow nearly $100 \mathrm{~km}$ long and several kilometers wide was observed in South Dakota using the National Oceanic and Atmospheric Administration's NOAA-14 Advanced Very High Resolution Radiometer (AVHRR) (http://cimss.ssec. wisc.edu/goes/misc/blsn.nd.html) and was observed in Iowa on 27 January 1997 (http://cimss.ssec.wisc.edu/goes/misc/ blsnia.html) and on 21 December 2000 (http://cimss.ssec. wisc.edu/goes/misc/001221.html) using NOAA-14 and NASA's Geodetic Earth Observing Satellite, GEOS-8. There is speculation that long convective rolls in the wind field give rise to these blowing snow bands, but their exact origin is uncertain.

\section{DISGUSSION}

The investigation illustrates InSAR's potential for mapping patterns of wind-drifted snow. The chief requirement, repeat orbits that are a few days apart, was met during the special research-oriented ERS-1 experiment of 1994. The 3 day repeat orbits of this phase were frequent enough to catch the swift snowpack changes caused by wind-terrain-snow interactions. The experiment occurred during an optimal period in mid-winter when the snowpack on the Alaskan arctic slope was cold, dry and likely to undergo drifting. Degradation of interferograms due to melting snow was absent, and the excellent control of the ERS-1 satellite orbit by ESA made it possible to construct consecutive interferometric pairs of SAR images with their satellite baselines within reasonable range for useful application.

During our investigation, we tested the applicability of pairs of ERS-1 SAR images with temporal separations of 3, 6, 9 and 12 days. Although the overall coherence decreased with increasing time, all separations produced usable interferograms as long as the satellite baselines were within a rea- 
sonable range $( \pm 0.5 \mathrm{~km})$. This experience makes us confident that interferometric pairs with shorter time intervals could also be used for similar investigations. Candidates for such investigations include those pairs obtained during the ERS1/-2 tandem missions between May 1995 and August 1996 when the twins ERS-1 and -2 followed the same InSAR repeat orbits with a time interval of only 1 day. Those closely spaced pairs might be ideal for catching swift changes in snow distribution that occurred within 1 day.

RADARSAT SAR images could also be used for this type of study. Although the repeat interval of 24 days of RADARSAT is twice as long as the 12 day interval that we tested during our study, investigations in other fields, such as earthquake (Massonnet and others, 1993) and volcano investigations (Massonnet and others 1995; Lu and others, 1997) and permafrost studies (Wang and Li, 1999), suggest that it is possible to produce useful interferograms from pairs of RADARSAT images. The steerable antenna of RADARSAT can generate eight or more interferometric pairs for a study site during a period of 2 months. Such a temporal coverage is much better than what is available from the ERS-1 or -2 satellites during their regular 35 day repeat phases outside their tandem missions. Of course, the interpretation of such interferograms could be problematic because many competing snow processes could occur during an interval of 24 days.

The results (Figs 7-10) suggest that wind redistribution of snow in a complex landscape is dependent not only on wind speed, direction and topography (generally considered), but also on the weather and the history of snow transport leading up to the redistribution event (less frequently considered). The combination of these variables constitutes a non-linear and highly complex system that defies precise modeling at this time. The InSAR method of "visualizing" areas of snow deposition and erosion we have described here is a promising tool for producing actual maps of redistribution of snow against which models could be tested. It is also likely that as our ability to interpret these InSAR results of snowdrifting improves, we will learn much about spatial patterns of wind drifting of snow.

\section{GONGLUSIONS}

Interferometry using SAR provides a unique method of investigating the interactions of wind, terrain and snow in the Alaskan Arctic. There, where wind storms are common and new snow layers pose minimum resistance to wind erosion, both large drifts and extensive areas of dunes, barchans and sastrugi form each winter. Patterns of drift redistribution created by erosion and deposition can be "visualized" or mapped over a wide range of scales using SAR coherence interferograms. Two key requirements are (1) that snowdrift events be bracketed by repeat orbit SAR acquisitions, and (2) that baseline separation of the two satellite passes be less than the maximum allowable baseline. Passes separated by 12 days were found to still be suitable for mapping changes in the snow. Calculations indicate that an $11 \mathrm{~cm}$ change in the surface elevation of the snow was needed to produce a $2 \pi$ difference in interferometric phase that was detectable; this corresponds with the development or migration of barchans or sastrugi about $5.5 \mathrm{~cm}$ high or more, a common occurrence in the region. If the $11 \mathrm{~cm}$ change in depth was spatially heterogeneous, total decorrelation could be achieved.
ERS-1 SAR interferogram sequences from three sites located south of Prudhoe Bay were collected in the winter of 1993/94 and compared to meteorological records and snowpit measurements made during the same period. The results were consistent with theoretical analysis, indicating little or moderate change by coherence when snowfall or windinduced changes in snow depth were $<11 \mathrm{~cm}$ for a typical dry snow cover with a density of $0.3 \mathrm{~g} \mathrm{~cm}^{-3}$, but distinctive changes when spatial variations in depth exceeded $11 \mathrm{~cm}$. The changes observed proved to be spatially complex, with alternating zones of scour and deposition that depended not only on terrain, wind speed and direction, but also on upwind fetch conditions and past wind, weather and snowfall history. Unusual interferometric streaks or bands, parallel with the wind direction and $3 \mathrm{~km}$ wide and $>30 \mathrm{~km}$ long, were observed during one notable blowing-snow event. These streaks appear to be bands of blowing snow separated by bands of clear air. Similar features have been observed in South Dakota and Iowa during blizzards, but the cause of these "rivers of drift" remains obscure and a good topic for future investigations.

\section{ACKNOWLEDGEMENTS}

Meteorological data were kindly provided by D. Kane and L. Hinzman. Precipitation data were provided by $\mathrm{R}$. McClure at the NRCS. J. Holmgren helped collect the snow-pit data. We thank the Alaska SAR Facility for assistance in acquiring ERS-1 SAR data. The work was supported by NASA grants NRA 97-MTPE-12 and NAG58614. The paper was improved by the comments of two anonymous reviewers and the Scientific Editor, H. Rott.

\section{REFERENCES}

Bambler, R. and P. Hartl. 1998. Synthetic aperture radar interferometry. Inverse Problems, 14(4), R1-R54.

Benson, C. S. 1982. Reassessment of winter precipitation on Alaska's Arctic Slope and measurements on the flux of wind blown snow. Fairbanks, AK, University of Alaska. Geophysical Institute. (Report 288.)

Benson, C. S. and M. Sturm. 1993. Structure and wind transport of seasonal snow on the Arctic slope of Alaska. Ann. Glaciol., 18, 261-267.

Black, R. F. 1954. Precipitation at Barrow, Alaska, greater than recorded. Transactions, American Geophysical Union, 35(2), 203-206.

Bürgmann, R., P. A. Rosen and E. J. Fielding. 2000. Synthetic aperture radar interferometry to measure Earth's surface topography and its deformation. Annu. Rev. Earth Planet. Sci., 28, 169-209.

Carsey, F. D., W. F. Weeks and the Alaska Sar Facility Prelaunch Science Working Team. 1989. Science plan for the Alaska SAR Facility program. Phase 1: Data from the first European Remote Sensing Satellite, ERS-1. Pasadena, CA, California Institute of Technology. National Aeronautics and Space Administration. Jet Propulsion Laboratory. (JPL Publication 89-14.)

Colbeck, S. C. and 7 others. 1990. The international classification for seasonal snow on the ground. Wallingford, Oxfordshire, International Association of Scientific Hydrology. International Commission on Snow and Ice.

Davis, T. N. and M. Sugiura. 1966. Auroral electrojet activity index AE and its universal time variations. 7. Geophys. Res., 71(3), 785-801.

De Sève, D., M. Bernier, J.-P. Fortin and A. Walker. 1997. Preliminary analysis of the snow microwave radiometry using the SSM/I passive microwave data: the case of La Grande River watershed (Quebec). Ann. Glaciol., 25, 353-361.

Doumani, G. A. 1967. Surface structures in snow. In Oura, H., ed. Physics of snow and ice. Vol. 1, Part 2. Sapporo, Hokkaido University. Institute of Low Temperature Science, 1119-1136.

Foster, J. L. and 9 others. 1996. Snow cover and snow mass intercomparisons of general circulation model and remotely sensed datasets. F. Climate, $\mathbf{9}(2), 409-426$.

Goita, K., A. Walker, B. Goodison and A. Chang. 1997. Estimation of snow water equivalent in the boreal forest using passive microwave data. In GER '97, International Symposium: Geomatics in the Era of RADARSAT, 24- 
30 May 1997, Ottawa, Ontario. Proceedings.Vol.1. Ottawa, Ont., Department of National Defence. Directorate of Geographic Operations, CD-ROM.

Goldstein, R. M., H. Engelhardt, B. Kamb and R. M. Frolich. 1993. Satellite radar interferometry for monitoring ice sheet motion: application to an Antarctic ice stream. Science, 262(5139), 1525-1530.

Goodison, B. E., H. L. Ferguson and G. A. McKay. 1981. Measurement and data analysis. In Gray, D. M. and D. H. Male, eds. Handbook of snow: principles, processes, management and use. Toronto, Ont., Pergamon Press Canada Ltd., 191-274.

Gray, A. L., K. E. Mattar and G. Sofko. 2000. Influence of ionospheric electron density fluctuations on satellite radar interferometry. Geophys. Res. Lett., 27 (10), 1451-1454.

Guneriussen, T., K. A. Högda, H. Johnsen and I. Lauknes. 2000. InSAR for estimation of change in snow water equivalent of dry snow. In Stein, T., ed. IGARSS 2000. 20th International Geoscience and Remote Sensing Symposium, 24-28 Fuly 2000, Honolulu, Hawaii, U.S.A. Proceedings. Vol. 2. Piscataway, NJ, Institute of Electrical and Electronics Engineers, 463-466.

Guneriussen, T., K. A. Högda, H. Johnsen and I. Lauknes. 2001. InSAR for estimation of change in snow water equivalent of dry snow. IEEE Trans. Geosci. Remote Sensing, GE-39(10), 2101-2108.

Jeffries, M. O., K. Morris, W. F. Weeks and H. Wakabayashi. 1994. Structural and stratigraphic features and ERS 1 synthetic aperture radar backscatter characteristics of ice growing on shallow lakes in NW Alaska, winter 1991-1992. f. Geophys. Res., 99(C11), 22,459-22,471.

Joughin, I., D. Winebrenner, M. Fahnestock, R. Kwok and W. Krabill. 1996. Measurement of ice-sheet topography using satellite-radar interferometry. F. Glaciol., 42(140), 10-22.

König, M. and M. Sturm. 1998. Mapping snow distribution in the Alaskan Arctic using aerial photography and topographic relationships. Water Res. Res., 34(12), 3471-3484.

Kuz'min, P. P. 1963. Snow cover and snow reserves. Jerusalem, Israel Program for Scientific Translations.

Li, F. K. and R. M. Goldstein. 1990. Studies of multi-baseline spaceborne interferometric synthetic aperture radars. IEEE Trans. Geosci. Remote Sensing, GE-28(1), 88-97.

Li, S., C. Benson, L. Shapiro and K. Dean. 1997. Aufeis in the Ivishak River, Alaska, mapped from satellite radar interferometry. Remote Sensing Environ., 60(2), 131-139.

Liston, G. E. 1986. Seasonal snow cover of the foothills region of Alaska's Arctic Slope: a survey of properties and processes. (M.Sc. thesis, University of Alaska, Fairbanks, AK.)

Liston, G. E. and M. Sturm. 1998. A snow-transport model for complex terrain. F. Glaciol., 44(148), 498-516.

Lu, Z. and 6 others. 1997. Deformation of New Trident Volcano measured by ERS-1 SAR interferometry, Katmai National Park, Alaska. Geophys. Res. Lett., 24(6), 695-698.
Massonnet, D. and K. L. Feigl. 1998. Radar interferometry and its application to changes in the Earth's surface. Rev. Geophys., 36 (4), 441-500.

Massonnet, D. and 6 others. 1993. The displacement field of the Landers earthquake mapped by radar interferometry. Nature, 364(6433), 138-142.

Massonnet, D., P. Briole and A. Arnaud. 1995. Deflation of Mount Etna monitored by spaceborne radar interferometry. Nature, 375(6532), 567-570.

Mätzler, C. 1996. Microwave permittivity of dry snow. IEEE Trans. Geosci. Remote Sensing, GE-34(2), 573-581.

Pomeroy, J.W. and D. M. Gray. 1995. Snowcover: accumulation, relocation and management. Saskatoon, Sask., Environment Canada. National Hydrology Research Institute. (NHRI Science Report 4.)

Prati, C. and F. Recca. 1990. Limits to the resolution of elevation maps from stereo SAR images. Int. F. Remote Sensing, 11 (12), 2215-2235.

Solaas, G. A. 1994. ERS-1 SAR interferometric baseline algorithm verification, version 2. Frascati, Italy, ESA/ESRIN. (ES-TN-DPE-OM-GS02.)

Sturm, M., J. Holmgren and G. E. Liston. 1995. A seasonal snow cover classification scheme for local to global applications. 7. Climate, 8(5), Part 2, 1261-1283.

Sturm, M., G. E. Liston, C. S. Benson and J. Holmgren. 2001. Characteristics and growth of a snowdrift in Arctic Alaska, U.S.A. Arct. Antarct. Alp. Res., $33(3), 319-329$.

Tabler, R. D. 1975. Estimating the transport and evaporation of blowing snow. In Snow Management on the Great Plains. Lincoln, NE, University of Nebraska, 85-105. (Great Plains Agricultural Council Publication 73.)

Tabler, R. D. 1980. Geometry and density of drifts formed by snow fences. 7 . Glaciol., 26(94), 405-419.

Taras, B., M. Sturm and G. E. Liston. 2002. Snow-ground interface temperatures in the Kuparuk River basin, Arctic Alaska: measurements and model. Hydrometeorology, 3, 377-394.

Ulaby, F. T., R. K. Moore and A. K. Fung. 1986. Microwave remote sensing, active and passive. Vol. 3. From theory to applications. Reading, MA, AddisonWesley Publishing Co.

Wang, Z. and S. Li. 1999. Detection of winter frost heaving of the active layer of Arctic permafrost using SAR differential interferograms. In Stein, T., ed. Remote sensing of the system Earth - a challenge for the 21st century. IGARSS '99, 19th International Geoscience and Remote Sensing Symposium, 28 June-2 July 1999, Hamburg, Germany. Proceedings. Vol. 4. Piscataway, NJ, Institute of Electrical and Electronics Engineers, 1946-1948.

Zebker, H. A. and R. M. Goldstein. 1986. Topographic mapping from interferometric synthetic aperture radar observations. 7. Geophys. Res., 91 (B5), 4993-4999.

Zebker, H. A. andJ. Villasenor. 1992. Decorrelation in interferometric radar echoes. IEEE Trans. Geosci. Remote Sensing, GE-30(5), 950-959.

Zebker, H. A., C. L. Werner, P. A. Rosen and S. Hensley. 1994. Accuracy of topographic maps derived from ERS-1 interferometric radar. IEEE Trans. Geosci. Remote Sensing, GE-32(4), 823-836. 